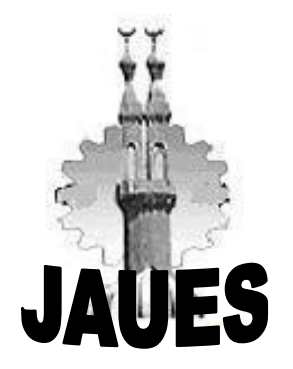

Journal Of Al Azhar University Engineering Sector

Vol. 12, No. 44, July, 2017, 878-885

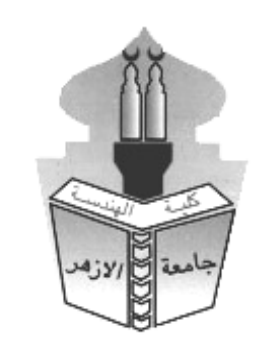

\title{
A COST ESTIMATION MODEL FOR MACHINING OPERATIONS; AN ANN PARAMETRIC APPROACH
}

\author{
Mostafa R. A. Atia ${ }^{1}$, Jean Khalil ${ }^{1}$ and Mahmoud Mokhtar ${ }^{2}$ \\ ${ }^{1}$ Mechatronics Dept., Faculty of Engineering, AASTMT, Cairo, Egypt. \\ ${ }^{2}$ Higher Technological Institute Tenth of Ramadan City, Cairo, Egypt
}

\begin{abstract}
The estimation of machining cost is one of the most important factors in the industry of metal products machining. Many approaches exist for the pre-calculation of the cost of machining for metal made products; but these approaches vary in complexity, requirements and therefore in their own cost. In recent years, the need for a cost effective methodology that intend to estimate the cost of machining of a given product has become more and more obvious; especially when the product is produced in small quantities where the cost of the study has to be kept to a minimum. In job shop facilities, precise classical cost calculation is too difficult due to the varieties infiniteness of workpieces in terms of features and of dimensions. A common practice is to calculate the manufacturing cost of the workpiece as a function in the machining time; however, machining time calculation itself is a costly and lengthy operation. More recently, the parametric estimation method has been adapted as a shorter way for estimation machining cost and / or time. This method needs much experience within the field of manufacturing, which lays in the human factor namely the expert. The experts judgments involve two drawbacks, first, it requires a good deal of acquired information; second the judgments are subject to evolution with the experts development.

In this paper, a new estimator based on the artificial neural network (ANN) is developed to replace both methods that relied either on the expert engineer or on the detailed process sheet for the assessment of machining time. The proposed tool uses the ANN to estimate the machining time using training cases, which are collected from real machining operations. The ANN input is a set of parameters related to the workpiece under consideration and to the specific cutting operation variables. The developed and trained ANN proved to be acceptably accurate in estimating the machining time of various case studies.
\end{abstract}

\section{Key words: Parametric study; Cost estimation; Machining operations; Artificial Neural Networks.}

2 INTRODUCTION

It is very common between metal manufacturers to face a special difficulty in assessing the cost of a machining process, therefore to inform the client. This problem becomes greater with small jobs since massive jobs usually involve enough funds for the classical complicated and costly study. The process of this calculation is labeled in literature as cost estimation.

Cost estimation is one of the most important factors in manufacturing products. Cost estimation can be described as the predictive process used to quantify, cost, and price the resources required by the scope of an asset investment option, activity, or project' [1].

The cost of running a piece of equipment may be estimated from the overall cost of running the whole factory through the commercial method [2]. Reference [3] confirmed the fact that nowadays 
the process of cost estimation for small manufacturing process is becoming a greater necessity with time; they also confirmed that the existence of such a feature at a reasonable cost and a reasonable degree of accuracy improves the company's competitiveness and increases the customer satisfaction. References [4] and [5] stressed on the fact that the miscalculations within this feature will lead to either a cost underestimation, which entails financial losses, or a cost overestimation, which will lead to missing business opportunities and making the integrity of the factory questionable. Reference [6] said that the step of cost estimation for manufacturing processes is crucial for a successful business. It was also added that the efficiency of this step is particularly critical when parts of the process are to be outsourced. References [7] and [8] suggested a featurebased analysis model where the expected cost is calculated based on the geometric shape and the dimensions of the required work piece.

\section{COST ESTIMATION METHODOLOGIES}

There are various cost estimation methodologies used throughout industry. In order to select a suitable cost estimation method, various parameters are considered, the most important of which are the availability of accurate information, and the existence of a timeframe. The Cost estimation methods may be classified into qualitative and quantitative methods. References [9] and [10] classified the cost estimation methodologies as described in table 1 .

Table 1 The classification of cost estimation methodologies

\begin{tabular}{|c|c|c|c|c|}
\hline Method & \multicolumn{2}{|l|}{ Characteristics } & Limitations & Remarks \\
\hline \multicolumn{5}{|c|}{$\begin{array}{c}\text { Qualitative Methods } \\
\end{array}$} \\
\hline $\begin{array}{l}\text { Human } \\
\text { based } \\
\text { Judgment }\end{array}$ & \multicolumn{2}{|c|}{$\begin{array}{l}\text { - Is a method of acceptable } \\
\text { accuracy. } \\
\text { - Consumes little time } \\
\text { - Does not require heavy } \\
\text { mathematical knowledge }\end{array}$} & $\begin{array}{l}\text { Applies only on small } \\
\text { lot sizes with a wide } \\
\text { variety of dimensions }\end{array}$ & $\begin{array}{l}\text { Depends much on the human } \\
\text { factor and is therefore subject } \\
\text { to the un-systemized human } \\
\text { judgment variability }\end{array}$ \\
\hline $\begin{array}{l}\text { Activity } \\
\text { Based } \\
\text { Costing } \\
\text { (ABC) }\end{array}$ & \multicolumn{2}{|c|}{$\begin{array}{l}\text { It deepens on the understanding } \\
\text { of the designers towards the cost } \\
\text { factors of their products. } \\
\text { Are relatively accurate. } \\
\text { Points at potential improvement } \\
\text { for profitability. }\end{array}$} & $\begin{array}{l}\text { - Is an expensive } \\
\text { approach. } \\
\text { - Consumes time } \\
\text { - Is a relatively } \\
\text { complicated } \\
\text { approach }\end{array}$ & $\begin{array}{l}\text { May be labelled expensive but } \\
\text { effective. }\end{array}$ \\
\hline \multicolumn{5}{|c|}{ Quantitative Methods } \\
\hline $\begin{array}{l}\text { Analogical } \\
\text { Cost } \\
\text { Estimation } \\
\text { Function }\end{array}$ & $\begin{array}{l}\text { - Consumes little time. } \\
\text { - Is based on actual } \\
\text { real data. } \\
\text { - Requires reasonably } \\
\text { small sets of data. } \\
\text { - Is reasonably } \\
\text { reflective of small } \\
\text { variations in data } \\
\text { values. }\end{array}$ & \multicolumn{2}{|c|}{$\begin{array}{l}\text { - Usually requires manual } \\
\text { adjustments. } \\
\text { - Its accuracy level is subject } \\
\text { to the fitting within the } \\
\text { available population of data. } \\
\text { - Does not take in } \\
\text { consideration any variation } \\
\text { in any cost factor. } \\
\text { - Is considerably more } \\
\text { complicated than parametric } \\
\text { methods. } \\
\text { - Does not allow any } \\
\text { alterations or improvements. }\end{array}$} & Is a comparative method \\
\hline $\begin{array}{l}\text { Parametric } \\
\text { Cost } \\
\text { Estimation } \\
\text { Methodolog } \\
\text { y (PCE) }\end{array}$ & - Consumes little time. & \multicolumn{2}{|c|}{$\begin{array}{l}\text { Requires excessive study of } \\
\text { the cost factors of a } \\
\text { component }\end{array}$} & $\begin{array}{l}\text { It evaluates the cost of the } \\
\text { product from characterizing } \\
\text { parameters, which do not } \\
\text { necessarily fully describe } \\
\text { every aspect of it. }\end{array}$ \\
\hline
\end{tabular}




\subsection{Artificial Neural Network Methodology (ANN)}

In comparison to the above-mentioned methods, the ANN is based on imitating the neuron transfer frameworks that exist in the human brain, especially those involved in the training and learning stages. The most popular networks are the Back Propagation Neural Network (BPNs), which are based on constant error feedback and modification of the weighted parameter approach to establish a minimum error estimation model. 'ANN techniques are widely applied to solve cost estimation problems in order to overcome the drawbacks of the regression-based model' [3]. References [11] and [12] states that the ANN was successful in many applications within the field of manufacturing cost estimation such as manufacturing of piping elements and vertical high speed machining centers. One of the main advantages of using neural networks in this application is its capacity to reduce uncertainties within the process of cost estimation. Ref [12] confirms that the ANN is able to construct high-level nonlinear function estimation models without limitations on the number of features. It also confirms that, it is agreed upon, that the ANN is simple in use and the output results are adequately consistent and accurate for the type of application under consideration. However, reference [13] claims that the training stage of the ANN requires a large number of samples and is time consuming.

\subsection{Problem Formulation}

The review of the available literature shows that a multitude of factors may be taken into consideration during the estimation of the overall cost of machining of a workpiece. The classical approach has always been to perform extremely long detailed calculative procedures. These procedures are based on material costs and machining times, which are in turn, calculated based on selected workpiece parameters. The costing varies with locations and evolves with time. Many attempts were done to decrease partially the cost estimation of machining process. These attempts relied on workpiece parameters and human experts' judgments.

The approach presented in this paper relies on using the machining time as the main component for the estimation of machining cost. The machining time does not change with years or places. The machining time will be calculated based on a parametric estimation method. Selected parameters of the machined part and machining process will be fed to an ANN in order to estimate the machining time. The ANN will be trained and evaluated by data sets from the industry.

\section{ARTIFICIAL NEURAL NETWORK:}

The Artificial Neural Network (ANN) is known to be a computational method, which imitates the biological nervous system. As shown in Figure 1(a), the process consists of inputs (like synapses), which are multiplied by weights (strength of the respective signals), and then computed by a mathematical function, which determines the activation of the neuron. Another function computes the output of the artificial neuron based on a certain threshold [14]. ANNs combine artificial neurons in a network in order to process information. Figure 1(b) shows a feed forward ANNs. In this network, the artificial neurons are organized in layers, which send their signals 'forward'. The network receives inputs by neurons in the input layer and the output of the network is given by the neurons in the output layer. There may be one or more intermediate hidden layers. The higher the weight of an artificial neuron is, the stronger the input, which is multiplied by this weight. Depending on the weights, the output of the neuron will be different. 


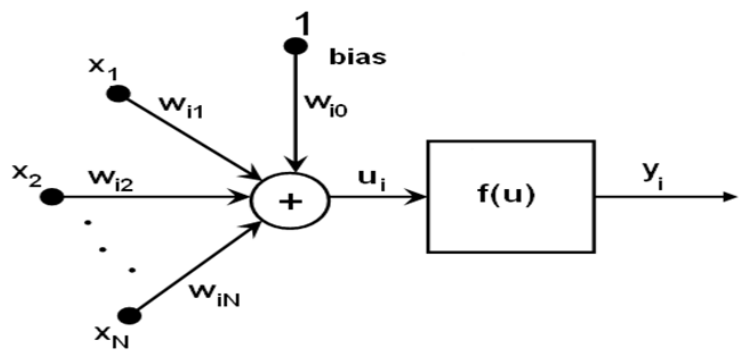

(a)

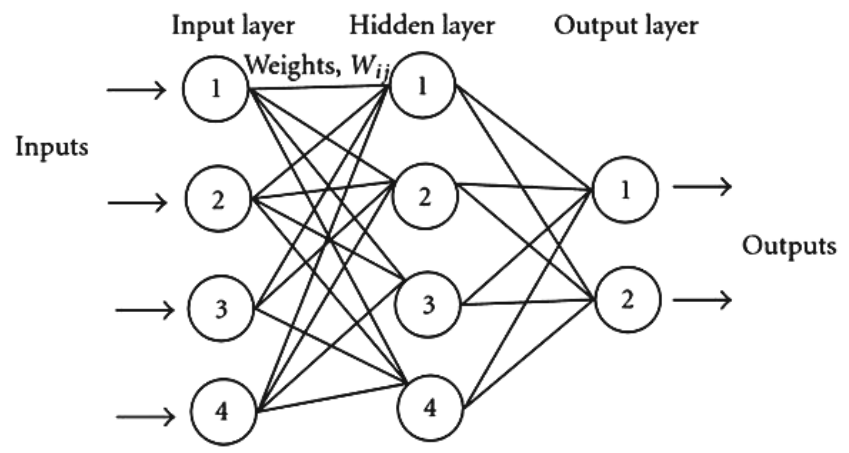

(b)

Figure 1. (a) Example of ANN [14] (b) Simple Feed forward ANN [14]

By adjusting the weights of an artificial neuron, the desired output can be obtained. The operation of adjusting the weights of the ANN is called learning or training. There are many training algorithms such as back error-propagation algorithm. It is used in layered feed forward ANNs. This algorithm is trained by sets of examples, which contain input arrays and the desired output arrays. The input is introduced to the network then the error between the actual and the desired output is propagated backward in the network to readjust the weights in order to reduce the error. Given the here mentioned mechanism, preparing the data set is the preliminary task in the process of design and training of ANN. Moreover, another data set is used for the verification and the testing of the developed ANN.

\section{DATA SET PREPARATION}

In this research, the inputs are the relevant machining variables, that are used to estimate the machining time and the output is the expected machining time. In addition,

Table 2 shows three examples of generating numeric values of input variables N1, N19 and N74 as per Figure 2.

Table 2 Inputs and related parameters applied on three workpieces.

\begin{tabular}{|c|c|c|c|c|c|c|c|c|c|c|c|}
\hline & \multirow{3}{*}{$\begin{array}{c}\text { Input } \\
\text { variable }\end{array}$} & \multirow{3}{*}{$\begin{array}{c}\text { Descriptio } \\
\mathrm{n}\end{array}$} & \multirow{3}{*}{ Range } & \multirow{3}{*}{ value } & \multirow{3}{*}{$\begin{array}{l}\text { Normalizing } \\
\text { function }\end{array}$} & \multicolumn{6}{|c|}{ Examples } \\
\hline & & & & & & \multicolumn{3}{|c|}{ Value } & \multicolumn{3}{|c|}{ Normalized value } \\
\hline & & & & & & N1 & N19 & N74 & N1 & N19 & N74 \\
\hline \multirow{6}{*}{1} & \multirow{6}{*}{ Volume } & \multirow{3}{*}{$\begin{array}{l}\text { Diameter, } \\
\mathrm{mm}\end{array}$} & $10-40$ & 0.25 & \multirow{6}{*}{$\stackrel{\vec{x}}{a}$} & 0.25 & & & \begin{tabular}{|l|}
0.125 \\
\end{tabular} & 0.5 & 0.25 \\
\hline & & & $40-180$ & 0.5 & & & 0.5 & 0.5 & & & \\
\hline & & & $180-250$ & 1 & & & & & & & \\
\hline & & \multirow{3}{*}{$\begin{array}{l}\text { Length, } \\
\mathrm{mm}\end{array}$} & $10-100$ & 0.25 & & & & & & & \\
\hline & & & $100-300$ & 0.5 & & 0.5 & & 0.5 & & & \\
\hline & & & $300-1000$ & 1 & & & 1 & & & & \\
\hline \multirow{5}{*}{2} & \multirow{5}{*}{ Weight } & \multirow{3}{*}{ Heavy } & Steel & 1 & & 1 & 1 & 1 & 1 & 1 & 1 \\
\hline & & & Cast iron & 0.9 & & & & & & & \\
\hline & & & Brass & 0.6 & & & & & & & \\
\hline & & \multirow{2}{*}{ Light } & Aluminum & 0.4 & & & & & & & \\
\hline & & & Teflon & 0.2 & & & & & & & \\
\hline \multirow{3}{*}{3} & \multirow{3}{*}{ Hardness } & Hard & & 1 & & 1 & 1 & 1 & 1 & 1 & 1 \\
\hline & & Medium & & 0.5 & & & & & & & \\
\hline & & Soft & & 0.25 & & & & & & & \\
\hline
\end{tabular}




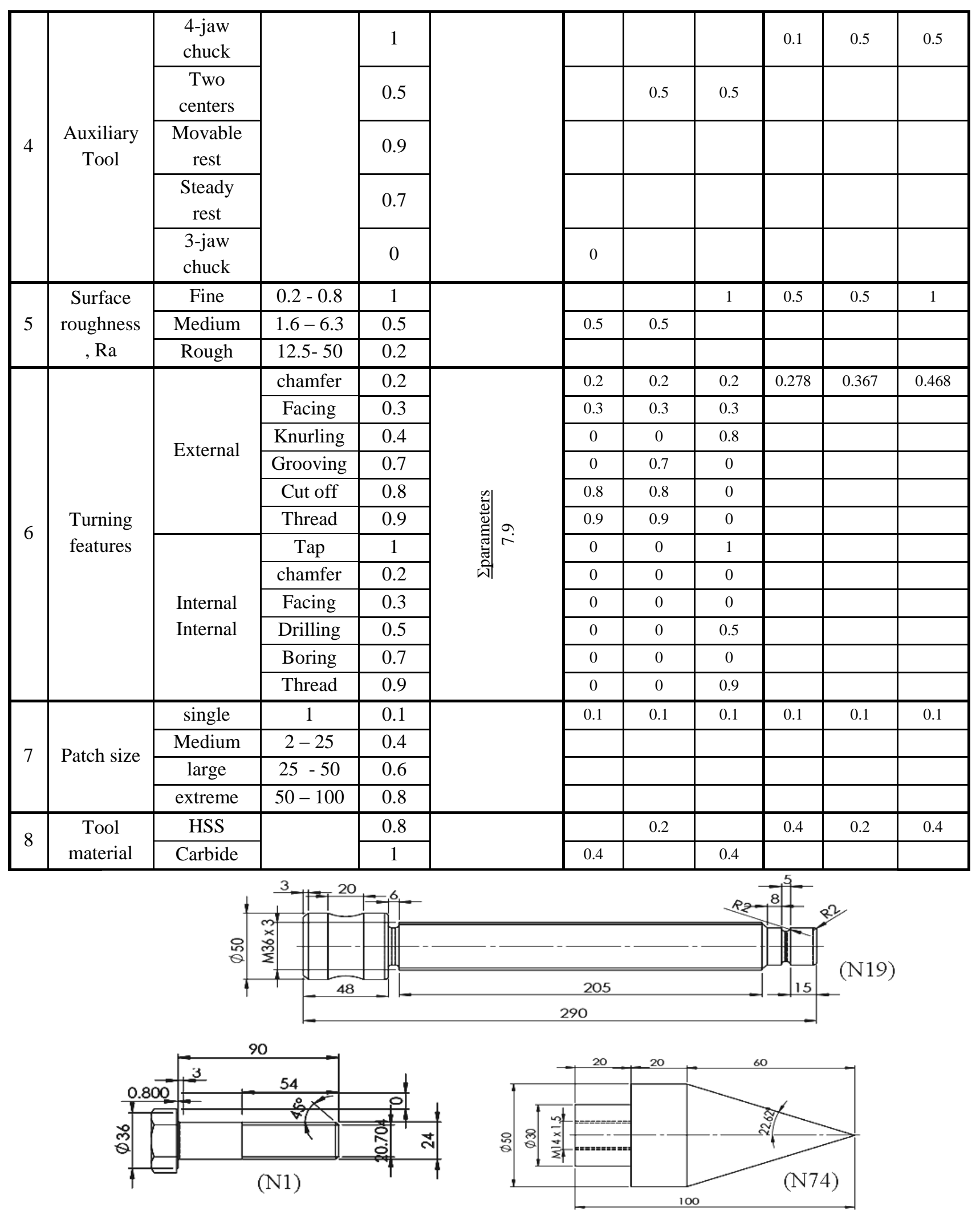

Figure 2 Examples of workpieces: N1, N19 and N74. 


\subsection{Output Data Preparation}

For every input data set, there is a desired machining time, which is the required outcome of the operation. The desired machining time was calculated by the traditional operation sheet method. The total machining time (TMT) of a part includes the times of direct machining, setting, handling, tool changing, speed and feed changing, measuring and rest. The calculated total machining time was normalized, using equation 1, to a value called normalized total machining time (NTMT) with maximum value of one. The total number of final data sets is shown in

Table 3.

$$
N T M T=\frac{T M T}{\text { Maximum expected TMT (300min) }}
$$

Table 3 Samples of the prepared data sets

\begin{tabular}{|c|c|c|c|c|c|c|c|c|}
\hline \multicolumn{2}{|c|}{ Workpiece code } & $\mathrm{N} 1$ & $\mathrm{~N} 20$ & $\mathrm{~N} 20$ & $\mathrm{~N} 34$ & $\mathrm{~N} 8$ & $\mathrm{~N} 87$ & $\mathrm{~N} 115$ \\
\hline \multirow{4}{*}{ Input variable } & 0.125 & 0.25 & 0.125 & 0.125 & 0.5 & 0.25 & 0.125 \\
\cline { 2 - 9 } & Weight & 1 & 0.8 & 1 & 0.2 & 1 & 0.6 & 1 \\
\cline { 2 - 9 } & Hardness & 1 & 0.5 & 1 & 0.25 & 1 & 0.5 & 1 \\
\cline { 2 - 9 } & Auxiliary tools & 0 & 0.5 & 0.5 & 0.5 & 0.5 & 0 & 0.5 \\
\cline { 2 - 9 } & Surface roughness & 0.5 & 0.5 & 0.5 & 0.5 & 0.5 & 0.5 & 0.5 \\
\cline { 2 - 9 } & Turning features & 2.2 & 3.4 & 2.9 & 2.1 & 3 & 2.7 & 2.7 \\
\cline { 2 - 9 } & Patch size & 0.1 & 0.4 & 0.1 & 0.1 & 0.1 & 0.1 & 0.1 \\
\cline { 2 - 9 } & Tool material & 1 & 0.8 & 1.8 & 0.8 & 1 & 1.8 & 1.8 \\
\hline \multirow{4}{*}{ Output parameter } & $\begin{array}{c}\text { Desired machining } \\
\text { time, min }\end{array}$ & 35.72 & 31.51 & 48.93 & 55.05 & 400 & 74 & 150 \\
\hline
\end{tabular}

\section{DESIGN OF THE ANN}

This section explains the design of the developed ANN as a feed forward ANN with three layers as shown in Figure 3. The first layer is the input layer, which consists of eight input neurons. The input layer is connected to hidden layer, which has a number of neurons. The output layer has one neuron, which gives the normalized total machining time.

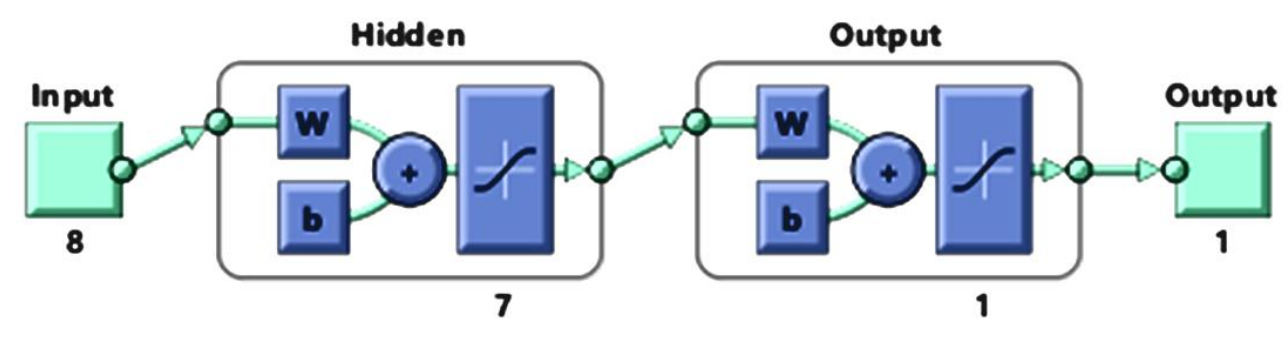

\section{$7 \quad$ Results and discussions}

Figure 3 One Hidden layer feed forward ANN

Table 4 shows the study of the regression values for the four developed networks. The different networks were developed based on transfer functions, activation functions, and the number of neurons. The network number net-8 was selected for its minimize regression value, which reflects its best capability of performing the required estimations. 
Table 4 A set of iterations for different Neural Networks

\begin{tabular}{|c|c|c|c|c|c|c|}
\hline network & $\begin{array}{c}\text { Transfer } \\
\text { Function }\end{array}$ & $\begin{array}{c}\text { Activation } \\
\text { Function }\end{array}$ & $\begin{array}{c}\text { Hidden } \\
\text { layer No. of } \\
\text { Neurons }\end{array}$ & $\begin{array}{c}\text { Test } \\
\text { regression }\end{array}$ & $\begin{array}{c}\text { Train } \\
\text { regression }\end{array}$ & $\begin{array}{c}\text { Overall } \\
\text { regression }\end{array}$ \\
\hline net-7 & tansig\&tansig & trainbr & 3 & 0.86115 & 0.90324 & 0.9007 \\
\hline net-8 & tansig\&tansig & trainlm & 7 & 0.93048 & 0.95873 & 0.95153 \\
\hline net-2 & tansig\&tansig & trainbr & 9 & 0.802 & 0.96159 & 0.9377 \\
\hline net-1 & tansig\&tansig & trainbr & 10 & 0.9434 & 0.9008 & 0.9212 \\
\hline
\end{tabular}

The developed ANN was trained using the prepared data set. The training was conducted with different numbers of neurons in the hidden layer. Those numbers were varied from 3 to 10 neurons. For training, $70 \%$ of the data set was used. The training operation was continued until the accuracy of the ANN calculations reached a preselected value of 0.0001 error, which is equivalent to 0.03 min. The error is the difference between the actual time of the job and the calculated output time of the ANN. Another $15 \%$ of the data set was used for the validation of the developed ANN. The remaining $15 \%$ of the data set was used for the validation of the developed ANN. Finally, the error that proved present at the testing stage was identified.

\section{CONCLUSION}

This paper targeted the solution of the problem of cost estimation for machining products through the estimation of a single parameter namely the machining time. It is claimed that this approach is advantageous over others, because the machining time can be generalized since it does not depend on local costing factors, nor does it evolve with time. The suggested solution cuts the cost of the study itself yet guarantees a very acceptable level of accuracy. In this research, a new method for estimating the machining time from machining operation variables was introduced. Eight parameters related to workpieces, machines and tools were selected according to a survey of a number of jobshop facilities. These parameters were categorized in ranges and were given normalized values.

The testing of developed and trained ANN showed that it was able to estimate the machining time with an error mean value of $10.2 \mathrm{~min}$ and a standard deviation of $17.42 \mathrm{~min}$. These figures are acceptable in job-shop work where the variability and uncertainty are high.

Using the developed ANN reduces the time of estimation of the machining cost and consequently the costing entailed by this time, since it overrules the necessity to study the details of machining operations and all the lengthily calculations. Moreover, the simple input variables reduce the need for highly expert engineers to accomplish the job of machining time estimation. The previous facts reduce the required time and cost of estimation of the machining cost for a workpiece. This developed methodology best suits cost estimation for machining jobs of small lot sizes. It is also useful to estimate the cost during product design and development. Finally, it is necessary to stress on the fact that increasing the number of data sets and their ranges will enhance the generalization and accuracy of this tool.

\section{REFERENCES}

[1] R. D. C. Larry, "An Introduction to Parametric Estimating," The Association for The Advancement of Cost Engineering, pp. 1-7, 2008.

[2] Hirohisa Narita, "A study of Automatic Determination of Cutting Cnditions to Minimize Machining Cost," SciVerse ScienceDirect, vol. 7, pp. 217-221, 2013.

[3] S. Deng and Tsung-Han Yeh, "Applying Least Squares Support Vector Machines to The Airframe Wing-Box Structural Design Cost Estimation," Elsevier, vol. 37, pp. 8417-8423, 2010. 
[4] Adnan Niazi, Jian S. Dai, Stavroula Balabani and Lakmal Seneviratne, "Product Cost Estimation: Technique Classification and Methodology Review," Manufacturing Science and Engineering, vol. 128, pp. 563-575, May 2006.

[5] S. Tang, D. Wang and F.-Y. Ding, "A New Process-Based Cost Estimation and Pricing Model Considering The Influences of Indirect Consumption Relationships and Quality Factors," Elsevier, vol. 63, pp. 985-993, 2012.

[6] C. Liu, Y. Li, W. Wang and W. Shen, "A Feature-Based Method for NC Machining Time Estimation," Elsevier, vol. 29, pp. 8-14, 2013.

[7] C. Ou-Yang and T. S. Lin , "Developing An Integrated Framework for Feature Based Early Manufacturing Cot Estimation," International Journal of Advanced Manufacturing Technology, vol. 13, pp. 618-629, 1997.

[8] Jung JJ, "Manufacturing Cost Estimation for Machined Parts Based on Manufacturing Features," Journal of Intelligent Manufacturing, vol. 13, pp. 227-238, 2002.

[9] M. Camargo, B. Rabenasolo, A-M. Jolly-Desodt and J-M. Castelain, "Application of The Parametric Cost Estimation in The Textile Supply Chain," Journal of Textile and Apparel, Technology and Management, vol. 3, no. 1, pp. 1-12, Summer 2003.

[10] P. D. Partha and R. Raikumar, "Cost modelling techniques for availability type service support contracts: A literature review and empirical study," ScienceDirect, Vols. 142-157, 2010.

[11] D. Orlando, M. Juan and R. Nibaldo, "Comparisons Between Two Types of Neural Netwroks for Manufacturing Cost Estimation of Piping Elements," Elsevier, vol. 39, pp. 7788-7795, 2012.

[12] J. Ciurana, G. Quintana and M.L. Garcia-Romeu, "Estimating The Cost of Vertical High-Speed Machining Centres, a Comparison Between Multiple Regression Analysis and The Neural Netwroks Approach," Elsevier, vol. 115, pp. 171-178, 2008.

[13] E. H. Tay and L. Cao, "Application of Support Vector Machines in Financial Time Series Forecasting," Omega, vol. 29, pp. 309-317, 2001.

[14] Lotfi A. Zadeh, Fuzzy and Neural Approaches in Engineering, John Wiley \& Sons Inc, 1997.

A. Layer, E. T. Brinke, F. V. Houten, H. Kals and S. Haasis, "Recent and Future Trends In Cost

[15] Estimation," Computer Integrated Manufacturing, vol. 15, no. 6, pp. 499-510, 2002.

[16] A. Mileham, G. Currie, A. Miles and D. Bradford, "A Parametric Approach to Cost Estimating at The Conceptual Stage of Design," Journal of Engineering Design, vol. 4(2), pp. 117-225, 1993.

[17] J. Bode, "Neural Network for Cost Estimation: Simulations and Pilot Application," International Journal of Production Research, vol. 38(6), pp. 1231-1254, 2000.

[18] A. L. John, "Parametric Cost Estimating in The New Millennium".Price Systems, LLC.

[19] P. Waston, R. Curran, A. Murphy and S. Cowan, "Cost Estiamtion of Machined Parts within an Aerospace Supply Chain," Concurrent Engineering: Research and Applications, vol. 14, pp. 17-26, March 2006.

[20] R. D. C. Larry, "Developing a Parametric Model for Estimating Process Control Costs," The Association for The Advancement of Cost Engineering, vol. 43, pp. 31-34, February 2001.

[21] Paul D. Collopy and Richard Curran, "The Challenging of Modeling Cost: The Problem," International Conference on Innovation and Integration on Aerospace Sciences, pp. 1-10, 4-5 Augest 2005. 